$$
\text { CONF-950956--11 }
$$

\title{
RF HIGH VOLTAGE PERFORMANCE OF RF TRANSMISSION LINE COMPONENTS ON THE DIII-D FAST WAVE CURRENT DRIVE (FWCD) SYSTEM
}

by

S.W. FERGUSON, R.W. CALLIS, W.P. CARY D.A. PHELPS, D. PONCE, F.W. BAITY, and G. BARBER
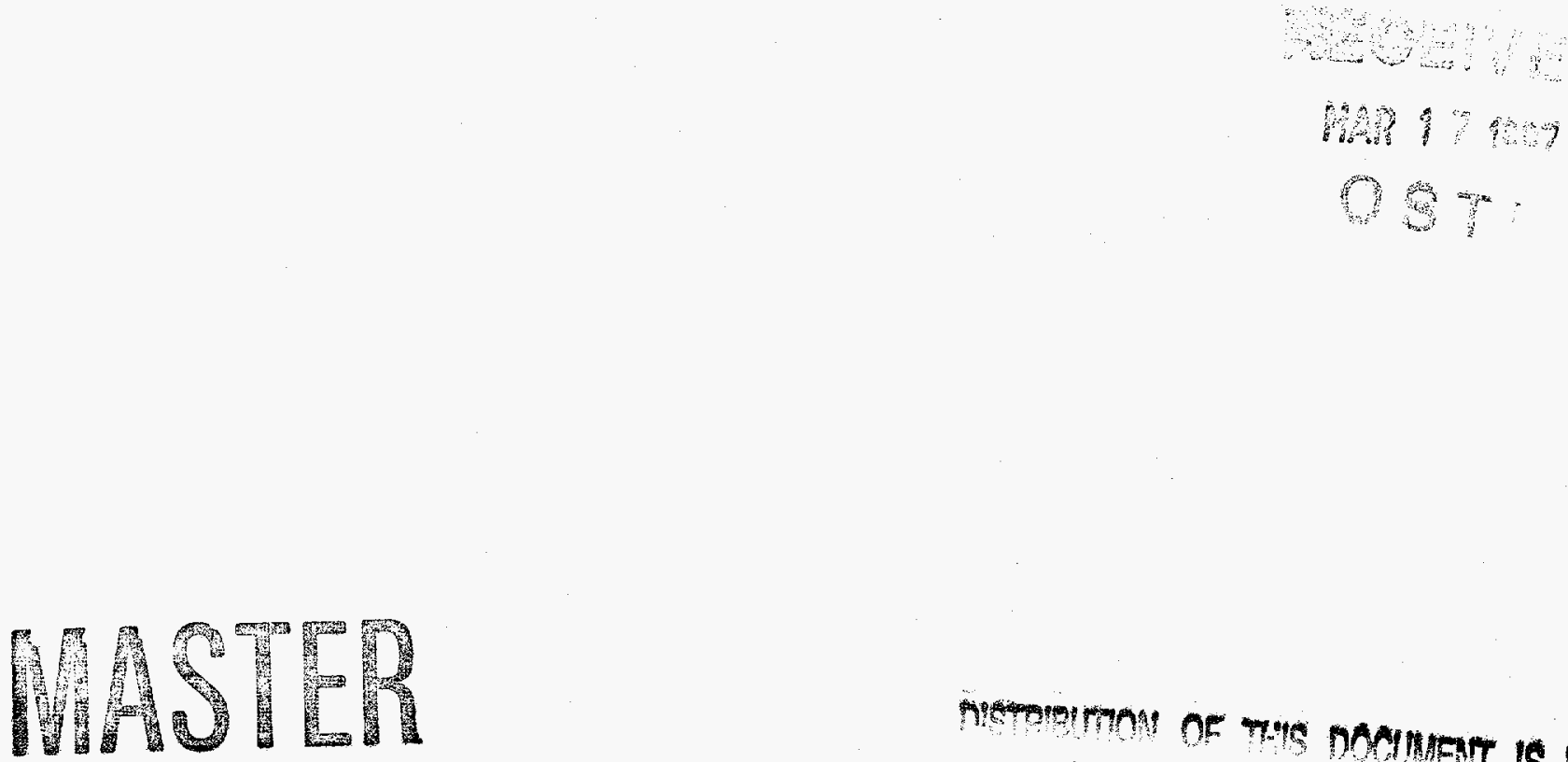

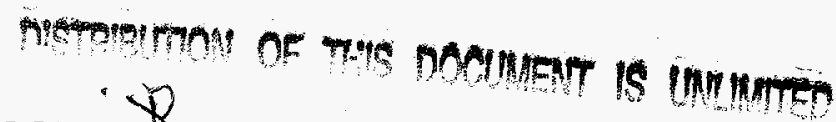




\section{DISCLAIMER}

This report was prepared as an account of work sponsored by an agency of the United States Government. Neither the United States Government nor any agency thereof, nor any of their employees, makes any warranty, express or implied, or assumes any legal liability or responsibility for the accuracy, completeness, or usefulness of any information, apparatus, product, or process disclosed, or represents that its use would not infringe privately owned rights. Reference herein to any specific commercial product, process, or service by trade name, trademark, manufacturer, or otherwise, does not necessarily constitute or imply its endorsement, recommendation, or favoring by the United States Government or any agency thereof. The views and opinions of authors expressed herein do not necessarily state or reflect those of the United States Government or any agency thereof. 


\section{DISCLAMMER}

Portions of this document may be illegible in electronic image products. Images are produced from the best available original document. 


\section{RF HIGH VOLTAGE PERFORMANCE OF RF TRANSMISSION LINE COMPONENTS \\ ON THE DIII-D FAST WAVE CURRENT DRIVE (FWCD) SYSTEM}

by

S.W. FERGUSON,* R.W. CALLIS, W.P. CARY

D.A. PHELPS, D. PONCE, F.W. BAITY, ${ }^{\dagger}$ and G. BARBER ${ }^{\dagger}$

This is a preprint of a paper presented at the 16th IEEE/NPSS Symposium on Fusion Engineering, September 30-October 5, 1995, Champaign, Illinois, and to be printed in the Proceedings.

Work supported by

U.S. Department of Energy Contracts W-7405-ENG-48, DE-AC03-89ER51114, and DE-AC05-840R21400

*Lawrence Livermore National Laboratory

†Oak Ridge National Laboratory

GENERAL ATOMICS PROJECT 3466

DECEMBER 1995 


\title{
RF High Voltage Performance of RF Transmission Line Components on the DIII-D Fast Wave Current Drive (FWCD) System*
}

\author{
S.W. Ferguson, ${ }^{a}$ R.W. Callis, ${ }^{b}$ W.P. Cary, ${ }^{b}$ D.A. Phelps, ${ }^{b}$ D. Ponce, \\ F.W. Baity, ${ }^{C}$ and G. Barber ${ }^{c}$ \\ ${ }^{a}$ Lawrence Livermore National Laboratory, P.O. Box 808, Livermore, California 94551-9900

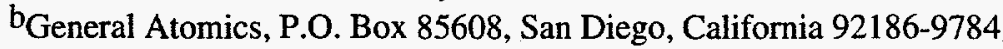 \\ ${ }^{c}$ Oak Ridge National Laboratory, Oak Ridge, Tennessee 37831
}

\begin{abstract}
The performance of the high voltage rf components of the DIII-D Fast Wave Current Drive System (FWCD) have been evaluated under various conditions of insulator configuration, insulator material, insulating gas and gas pressure. The insulator materials that have been investigated are alumina, steatite, pyrex, quartz, and teflon. The results of this evaluation are discussed in this paper. Additionally a rf high potter was developed to aid in the evaluation of $\mathrm{rf}$ high voltage components. The high potter consists of a $50 \Omega, 1 / 4$ wavelength cavity with a variable position short and a $50 \mathrm{ohm}$ matched tap at one end of the cavity. With this configuration $\mathrm{rf}$ voltages were generated in excess of $100 \mathrm{kVp}$ in the frequency range 30 to $60 \mathrm{MHz}$.
\end{abstract}

\section{INTRODUCTION}

The coaxial transmission line components for the DIII-D Fast Wave Current Drive (FWCD) System were purchased from Dielectric Communications and RF Technologies. The components were delivered to General Atomics (GA) in early 1994. Some of the components were fabricated in $9 \mathrm{in}$., $50 \Omega$, transmission line while other components were fabricated in 6 in., $25 \Omega$, transmission line. The specification to the vender indicated that the lines were to use alumina ceramic insulators, no hydrocarbons or plastics, and that the transmission line components were to be dc high potted at the vender manufacturing facility. Alumina was chosen because it was used in other high power rf systems and it had superior mechanical strength characteristics as compared to other ceramics. Since no rf high voltage test capability existed at the vender or at GA facilities that could generate if voltages near the rf operating levels for the transmission line components, the transmission line venders were required to test the components to a voltage that was twice the highest peak radio frequency (rf) voltage that the components could experience in operation. This specification for 9 in. components was to high pot the components to $140 \mathrm{kV} \mathrm{dc}$ in $45 \mathrm{psi}$ SF6 gas and the specification for 6 in. components was to test to $100 \mathrm{kV}$ dc in $45 \mathrm{psi}$ SF6 gas. All of the components passed the dc high pot test at the vender facility with little or no difficulty.

The system was installed and operation started in July 1994. Fig. 1 shows a line diagram of one of the two General
Atomics transmitters and transmission line systems to the antennas. The first system test was to rf condition the transmission lines into the antennas in the DIII-D vacuum vessel. During this first test we experienced arcing in the transmission line at fairly low rf voltages (about $8 \mathrm{kV}$ peak). Repeated operation of the components under rf voltage for conditioning did not seem to increase the voltage breakdown in the transmission lines and some of the insulators started to degrade due to repeated arcing. Since the insulators were breaking down at a unexpedly low rf voltage, an investigation of the cause of the failures was started.

The first neccessity was a means to conveniently generate high rf voltages across an insulator in a gas pressurized system while using a fairly low power rf source. The system also had to be mechanically simple, easily adjusted to a desired frequency, and had to match the system to the $50 \Omega$ transmitter if source impedance. The if high voltage test fixture shown in Fig. 2 to was designed to meet these objectives. The test fixture was built in four sections. The first section on the left side of the figure is a variable $50 \Omega$ tap. The sliding short is moved until the impedance at the $50 \Omega$ coax input is exactly a $50 \Omega$ matched impedance. This section also contains the gas injection fittings to allow pressurization of the test fixture. Fig. 3 is a more detailed sketch of the variable $50 \Omega$ tap section. The next section is a length of $50 \Omega, 9 \mathrm{in}$. diameter, transmission line. The length of the line is set to bring the test fixture to resonance on the desired operating frequency. Section 3 of the test fixture is a custom section designed to hold the rf insulator under test and to mate to the other parts of the high voltage tests fixture. The last section of the test fixture contains a screened viewing window and a capacitively coupled high voltage probe. The voltage step up from the $50 \Omega$ tap to the high voltage end is approximately equal to the square root of the $Q$ of the resonator. The $Q$ of the resonator is primarily limited by the copper losses in the sliding short and to a lesser extent the copper losses in the 1/4 wavelength resonator section. By building the resonator from $50 \Omega, 9$ in. diameter, copper transmission line, a resonator $Q$ of about 1200 to 1700 in the 30 to $60 \mathrm{MHz}$ frequency range was achieved. This equated to a voltage step up of about 40 times from the $50 \Omega$ point to the high voltage tip. A input power of $20 \mathrm{~kW}$ generated about $56 \mathrm{kV}$ peak on the insulator under test.

\footnotetext{
*Work supported by the U.S. Department of Energy under Contract Nos. W-7405-ENG-48, DE-AC03-89ER51114 and DE-AC05-84OR21400.
} 


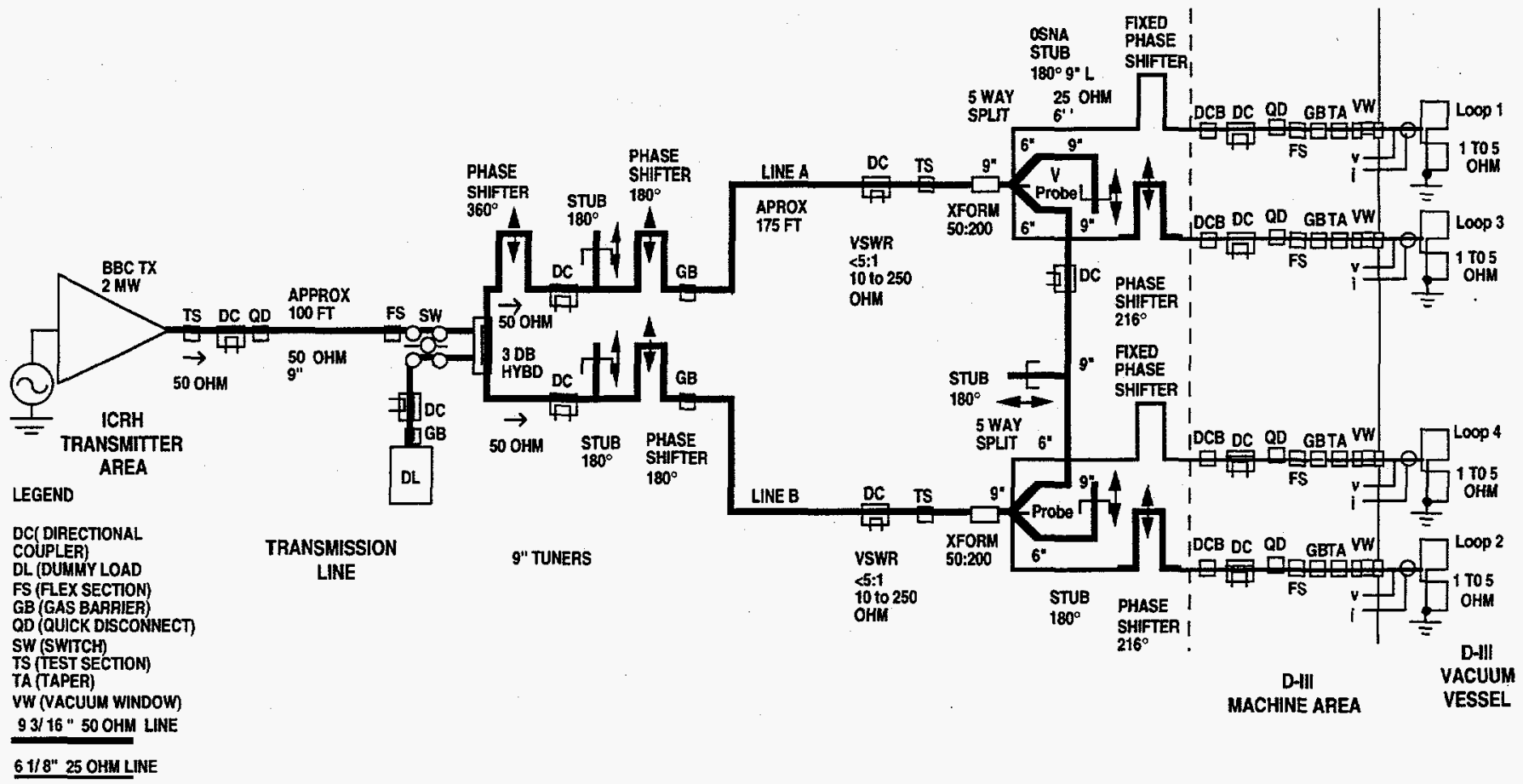

Fig. 1. D-IIID Transmission Line and Antenna Tuners

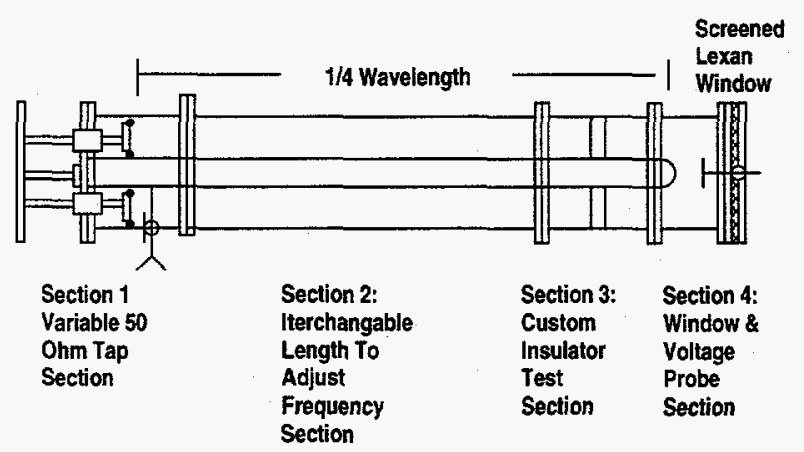

Fig. 2. RF High Voltage Resonator (Four Sections)

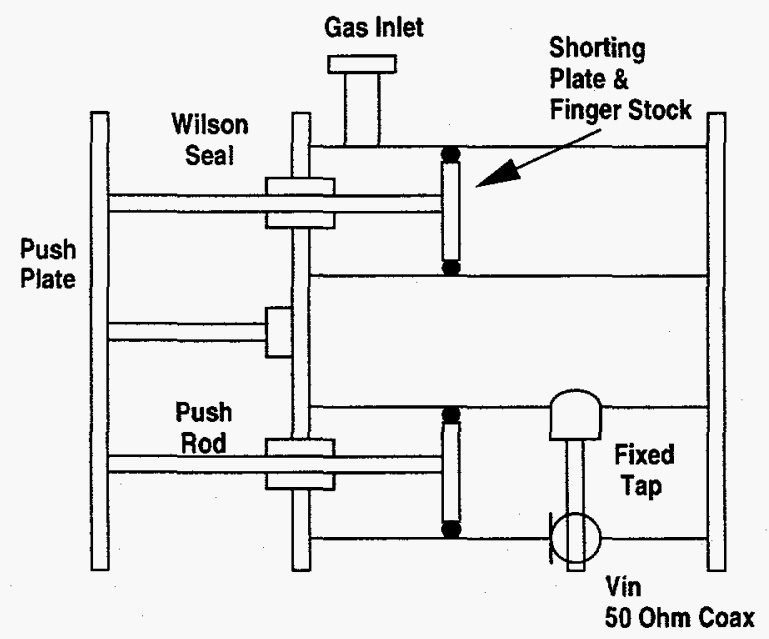

Fig. 3. Movable end plate and $50 \Omega$ tap.
New insulators were fabricated from alumina, steatite, pyrex, quartz, and teflon to characterize their breakdown characteristics. The first test were conducted in ambient air to establish any obvious breakdown trends. Some of the insulators were tested with corona rings or metalized ends to help prevent breakdown. Fig. 4 is a summary plot of these tests. The clear trend in this data is that the breakdown voltage of the insulator is inversely proportional to the dielectric constant. The lower the dielectric constant of the material the higher the breakdown voltage. The peak voltage for this test was limited by the breakdown of the ambient air. Both teflon and quartz, the lowest dielectric constant materials, broke down at a voltage nearly equal to an equivalent air gap, while the high dielectric constant materials were much more prone to breakdown. From this data we concluded that alumina was an inherently poor choice for the rf insulators in the transmission line components. The electric field enhancements at the gas, metal, ceramic triple points due to the high dielectric constant of the alumina was a significant problem. The breakdown could be mitigated by a proper design of the corona rings and a complicated field gradient structure, however, it seemed far simpler to change the insulator material to a material such as quartz that would eliminate the problem without significant mechanical redesign.

\section{CONCLUSION}

Tests were then conducted on the various insulator materials in the presence of gases at different pressures. Fig. 5 is a summary of these tests. The combination of SF6 gas and the quartz insulator was the best for arc suppression, and this was selected for implementation in all the coaxial transmission 


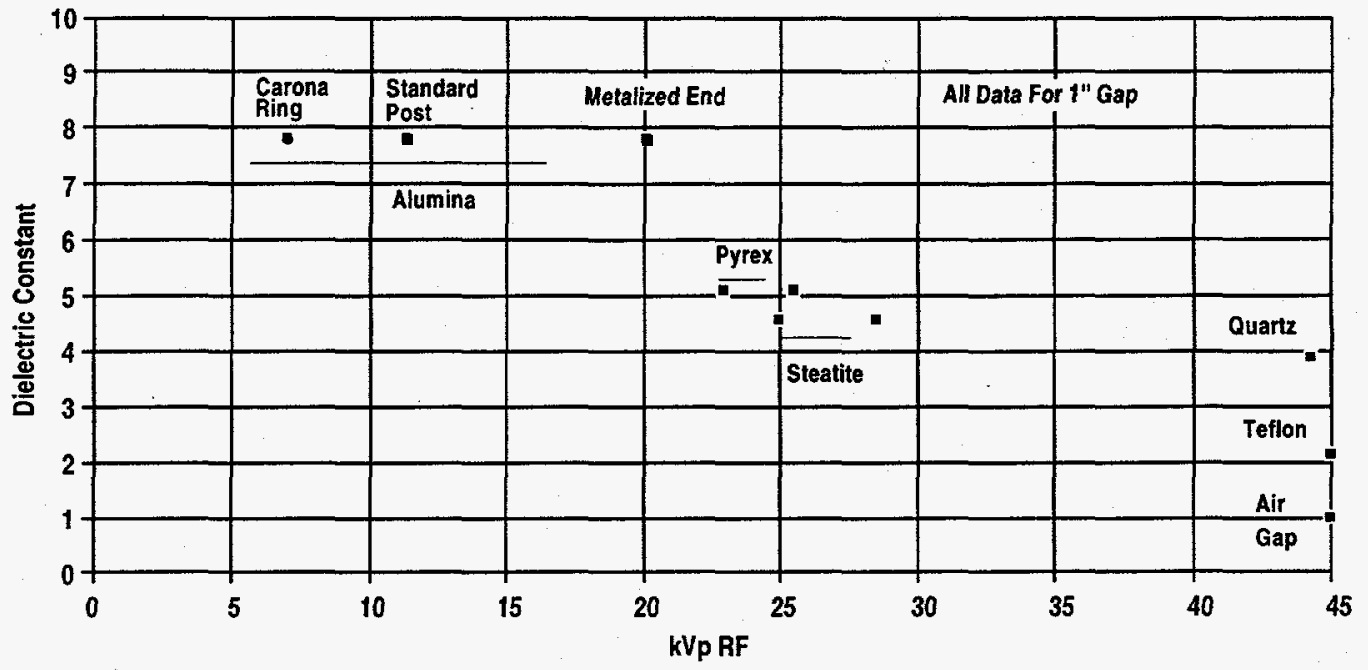

Fig. 4. RF breakdown voltage vs. dielectric constant.

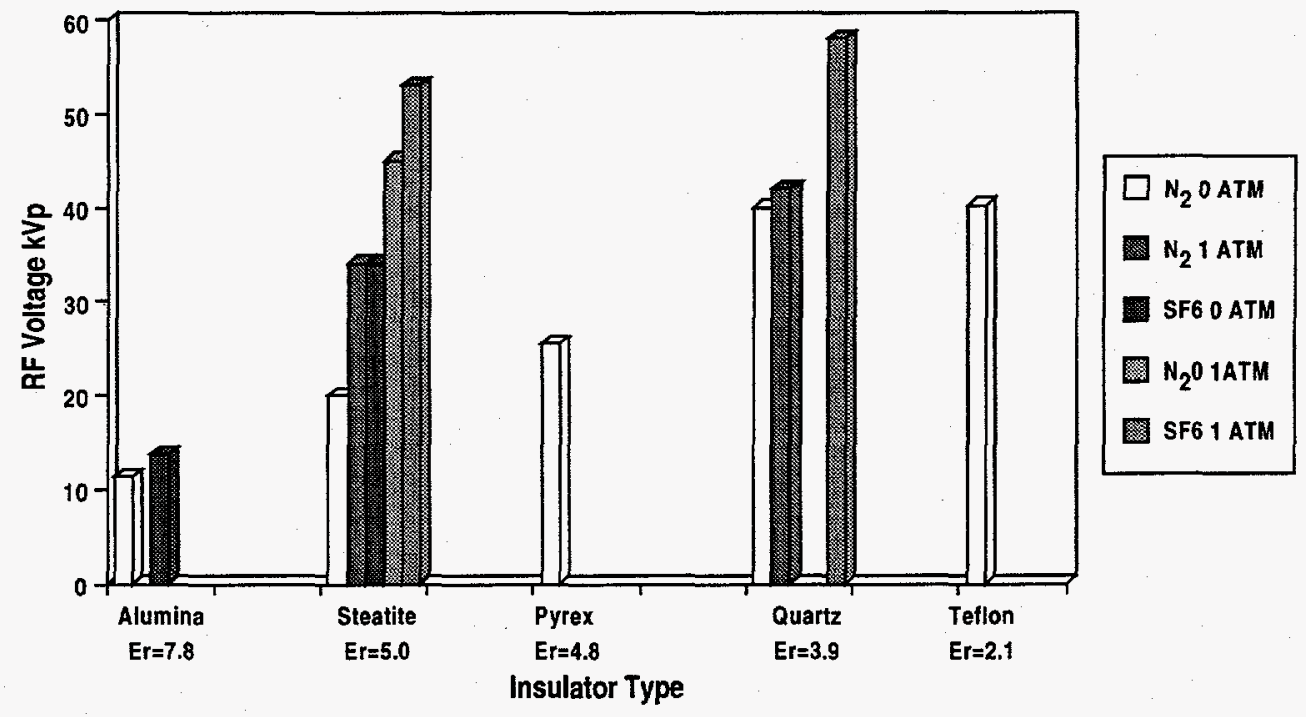

Fig. 5. RF breakdown voltage vs. insulator and gas.

line sections. The insulators associated with the special components of the DIII-D fast wave current drive system were tested for high voltage breakdown. All insulator configurations in the DIII-D fast wave current drive system have been tested with the $\mathrm{rf}$ high potter. The insulators in the $50 \Omega$ transmission line components have been tested successfully to at least $72 \mathrm{kVp}$ while the $25 \Omega$ components have been tested successfully to at least $50 \mathrm{kVp}$. All tests were performed in 15 psig SF6. 